\title{
Investment risk analysis of electricity generation from vinasse biodigestion in the Brazilian Regulated Market
}

\author{
Luane Schiochet Pinto, Daywes Pinheiro Neto, Elder Geraldo Domingues \\ Master Program in Sustainable Process Technologies \\ Federal Institute of Goiás (IFG) \\ Campus of Goiânia - Goiás, 74900-000, Brazil \\ Phone/Fax number:+0055 623327 2769, e-mail: luane.schiochet@hotmail.com
}

\begin{abstract}
This paper presents a methodology of investment risk analysis of the electricity generation by using biogas from biodigestion of sugarcane vinasse produced in sugarcane agroindustries. The methodology to be presented uses econometric models to generate synthetic time series of ethanol production, which is used to estimate the production of vinasse, biogas and electricity. The economic viability analysis will be done from the evaluation of the probability distribution functions of Net Present Value, Modified Internal Rate of Return and Discounted Payback, by considering that the electricity produced is commercialized in the Brazilian Regulated Contracting Environment. A case study is carried out using real data from a sugarcane plant located in the Midwest region of Brazil. The results indicate the economic viability of the project implementation.
\end{abstract}

Key words: Biogas; Brazilian Regulated Contracting Enviroment; Risk Analysis; Vinasse.

\section{Introduction}

The need for diversification of the Brazilian energy matrix has increasingly encouraged the insertion of wind, solar and biomass energy from agroindustries, landfills, sewage treatment plants and pig farms.

Sugarcane agro-industries generate large amounts of waste such as sugarcane bagasse, straw, ash, filter cake and vinasse during the production process of ethanol and sugar [1]. For each liter of ethanol produced is generated from 7 to 15 liters of vinasse [2]. Nowadays this byproduct is used in the fertirrigation of sugarcane replacing the use of fertilizers. However, the displacement cost is high when it comes to areas far from the plant, which causes it to be dumped in large quantities in the same place, damaging the soil and groundwater [3].

One of the ways to minimize the effects of improper vinasse disposal is anaerobic biodigestion. This process has the biogas as a byproduct, which can be used to generate electricity in a clean and efficient way, minimizing waste in the sector. This form of electricity generation is complementary to the hydroelectric energy, since the sugaralcohol harvest coincides with the dry season [4].
Most of the studies that analyze the technical and economic viability of the biogas energy utilization from the vinasse biodigestion use deterministic methods, which are considered simplified when it comes to decision support. In [5], the author presents a deterministic technical and economical feasibility study of the use of vinasse for the production of electricity based on the Internal Rate of Return (IRR), Net Present Value (NPV) and Discounted Payback. These criteria indicate the economic viability of the project both for the sale of energy to the local distribution company and for own consumption, thus avoiding the cost of buying energy.

In [6] it is presented an estimate of the potential of electricity generation from the biogas burning from the anaerobic biodigestion process of the vinasse. The authors conclude that there is a great potential of generation, which can supply part of the energy demand of the agroindustry analyzed.

Risk analysis considers the random variables involved in the process, offering a broad approach and risk information to support decision making. In this way, this paper presents a methodology of risk analysis for the economic viability analysis of electricity generation projects that use the biogas from the biodigestion of vinasse in sugarcane plants. It was considered that the electric energy produced is commercialized in the Regulated Contracting Environment (RCE) of the Brazilian electricity market. The proposed methodology will contribute greatly to the decision-making process of these types of projects.

\section{Methodology}

To validate the proposed methodology, a case study was conducted for a sugarcane agroindustry located $170 \mathrm{~km}$ from Goiânia, city located in the Midwest region of Brazil.

The general flowchart of the methodology is shown in Figure 1. 
From the historical data of the random variable ethanol production, it is possible to apply statistical tests [7], [8] in order to obtain the most appropriate stochastic process, as well as to estimate its parameters. The Monte Carlo method is applied in the stochastic model to generate the synthetic series [8]. Simulations are performed for 2000 forecast scenarios, with the number of monthly periods equal to the project's useful life.

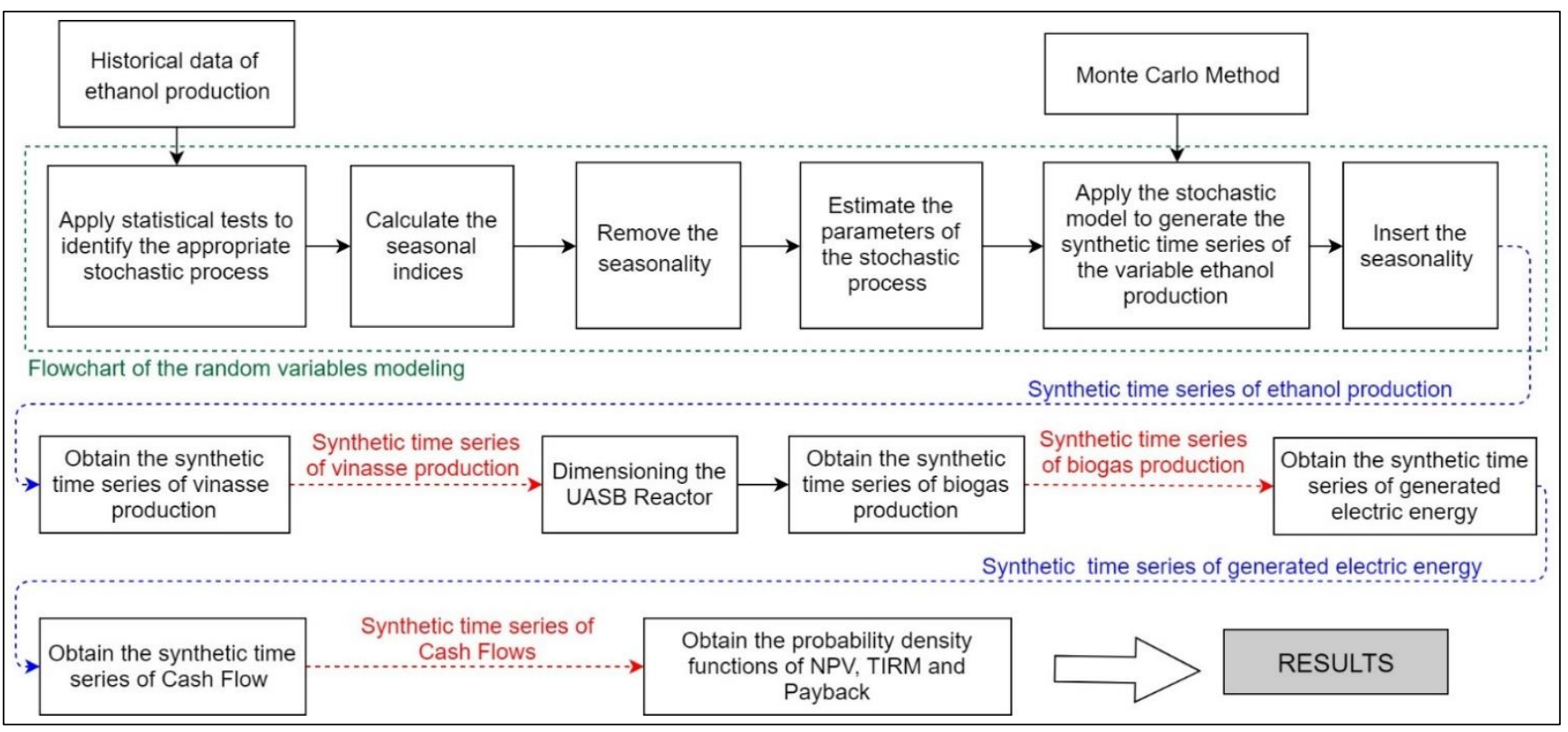

Fig. 1 - General flowchart of the methodology.

\section{A. Stochastic Model of the Random Variable Ethanol Production}

The statistical tests of Dickey-Fuller (DF) and Variance Ratio performed for the random variable ethanol production was done in [9] and indicated the suitability of the use of the mean reversion model.

Ehanol production is a variable that presents seasonality over time. In order to estimate the parameters of the model it is necessary to remove this effect. From the historical data, the seasonality indexes can be calculated, through the relationship between the averages of historical values of a specific month and the average of all historical values [9]. The parameters of the stochastic model were obtained through simple linear regression.

The arithmetic mean-reversion model with inclusion of the seasonality index of the random variable ethanol production is presented in (1).

$$
E_{S_{t+1}}=\left\{E_{t}+\eta_{E}\left(\bar{E}-E_{t}\right) d t+\sigma_{E} \cdot \varepsilon_{E} \cdot \sqrt{d t}\right\} \cdot I_{E_{m}}
$$

In (1), $E_{S_{t+1}}$ is the ethanol production at period $t+1$, with seasonality; $E_{t}$ ethanol production at an instant $t$, without seasonality; $\eta_{E}$ is the mean reversion speed to the average value of ethanol production $\bar{E} ; \sigma_{E}$ is the volatility of the ethanol production; $\varepsilon_{E} \cdot \sqrt{d t}$ is the Wiener process of the ethanol production, wherein $\varepsilon_{E} \sim N(0,1)$, and $I_{E_{m}}$ is the monthly seasonal index of the ethanol production.

\section{B. Vinhaça Production Estimation}

Based on the annual historical data of ethanol and vinasse production, it is possible to calculate the constant $k_{V E}$, given by the the ratio between the quantity of vinasse generated per liter of ethanol during the distillation process. Such a constant will be used to generate the synthetic time series of the vinasse production potential, given by (2).

$$
V_{t+1}=k_{V E} \cdot E_{S_{t+1}}
$$

In (2), $V_{t+1}$ is the amount of vinasse produced in the ethanol manufacturing process at period $t+1$, in $m^{3} /$ month.

\section{Electricity Generation Potential}

The biogas production is directly related to the volume of the reactor. Biogas from vinasse biodigestion is determined by the relationship between the volumetric production of methane and the concentration of methane in the residue [9].

To determine the potential of electricity generation it is necessary to obtain the monthly available electrical power $\left(\boldsymbol{P}_{\boldsymbol{E}_{\boldsymbol{t}+1}}\right)$, given by (3).

$$
P_{E_{t+1}}=\left(P_{\text {biogás }_{t+1}} \cdot P C I_{\text {biogás }} \cdot \eta_{G M G}\right) / 720
$$

In (3), $P_{\text {biogás }}+1$ is the biogas production estimation at period $t+1 ; P C I_{\text {biogás }}$ is the lower calorific value of biogas $\left(k w h / m^{3}\right) ; \eta_{G M G}$ is the efficiency of the applied technology (\%), and 720 is a constant that represents the number of hours in 1 month.

For this study, the Otto-Cycle Motor Generator Group (MGG) technology was used, due to the low acquisition 
and maintenance costs, besides being a technology available throughout the country.

From the available electrical power, the monthly electricity generation can be determined, taking into account the number of operation hours of the technology employed, given by (3).

$$
E_{E_{t+1}}=P_{E_{t+1}} \cdot N_{H}
$$

In (3), $E_{E_{t+1}}$ is the generated electricity at period $t+$ $1(k W h)$ and $N_{H}$ is the number of operating hours of the electric power generation technology.

\section{Cash Flow}

The cash flow model used, adapted from [10], is presented below.

(+) Gross Revenue Sale of electricity

(-) Gross Revenue Taxes PIS $^{1}$

COFINS $^{2}$

(=) Net Revenue

(-) Operational Expenses Operation \& Maintenance (O\&M) Costs Depreciation of equipment Sectoral charges

(=) Profit Before Income Tax (PBIT)

(-) Taxes Income Tax Social Contribution over Net Profit (CSLL) ${ }^{3}$

(=) Net Profit after Income Tax

(+) Depreciation of equipment

(-) Investment

(=) Net Cash Flow

${ }^{1}$ In Brazil, PIS refers to Social Integration Program, a tax levied on corporations' total sales, created in 1970. PIS/PASEP refers to the unification of PIS with PASEP (Public Servant Fund) occurred in 1975.

${ }^{2}$ In Brazil, COFINS refers to Social Security Financing Contribution - an additional mandatory contribution to the financing of social security, based on the gross turnover of corporations.

${ }^{3}$ In Brazil, CSLL refers to another federal tax levied on corporations for the financing of social security.

It is considered that all electricity produced will be commercialized in the Regulated Contracting Environment (RCE) at a fixed price, which is determined through auctions of purchase and sale of electricity. In this way, the gross revenue from the sale of electricity is obtained through (4).

$$
R B_{t+1}=E_{E_{t+1}} \cdot \$_{E E}
$$

In (4), $R B_{t+1}$ represents the gross revenue from the sale of electricity in the period $t+1, \$_{E E}$ the electricity price from the auction.

\section{E. Economic Viability Indicators}

To carry out the investment analysis, economic indicators are used, which reflect the behavior of the cash flow during the life of the project.

The probability distribution of the following indicators will be obtained: i) Net Present Value (NPV), ii) Modified Internal Return of Return (MIRR), and iii) Discounted Payback. From the probability distributions of each indicator it is possible to calculate, among others, the expected values and the standard deviations. The standard deviations corresponds to the risk of the investment.

\section{1) Net Present Value (NPV)}

The most used indicator in investment project analysis is the NPV, which determines the impact of future events related to the investment in terms of present value. When the NPV is positive means that the investment is feasible. Otherwise, the investment is unfeasible [10].

The amount of NPV values in a risk analysis is equal to the amount of scenarios k generated, given by (5).

$$
N P V_{(k)}=\sum_{i=1}^{n} \frac{F C_{i(k)}}{(1+M A R R)^{i}}
$$

In (5), $N P V_{(k)}$ is the net present value for the scenario $k$, $F C_{i(k)}$ is the cash flow in period $i$ and scenario $k, n$ is the number of monthly periods during the project's lifespan, and MARR represents the Minimum Attractiveness Rate of Return applied to the cash flow.

\section{2) Modified Internal Rate of Return (MIRR)}

The Internal Rate of Return (IRR) is the rate that makes the net present value of an investment project equal to zero, that is, the rate at which the present value of the revenue amounts are equal to the present value of expenses of the project [11].

However, more than one value can be found for IRR. It occurs when the cash flow of the project has more than one signal inversion [12]. Thus, it is necessary to use the MIRR, given by (6), which seeks to correct structural problems related to multiple roots. The modified internal rate of return uses two rates, known as the financing rate and the investment rate [10].

$$
M I R R_{k}=\left[\frac{\sum_{i=0}^{n} F C P_{i(k)}\left(1+R_{i}\right)^{n-i}}{\frac{\sum_{i=0}^{n}\left|F C N_{i(k)}\right|}{\left(1+R_{f}\right)^{i}}}\right]^{\frac{1}{n}}-1
$$

In (6), $F C P_{i(k)}$ are the positive cash flows for the period $i$ and scenario $k, F C N_{i(k)}$ are the negative cash flows for the period $i$ and scenario $k, R_{i}$ is the investment rate, $R_{f}$ is the financing rate and $n$ is the number of monthly periods during the lifespan of the project. 
The Minimum Attractiveness Rate of Return (MARR) is the minimum rate of return that the investor is willing to accept before starting the new project, considering its risk. According to this indicator, the project is viable when the MARR is less than MIRR (or IRR).

\section{3) Discounted Payback}

According to this indicator, a project is economically feasible only if the investment can be recovered before the end of the project's lifespan [12]. The Discounted Payback considers the value of the money in time, and can be calculated by using (7).

$$
\operatorname{Payback}_{(k)}=\sum_{i=1}^{n} \frac{\left|F C N_{i(k)}\right|}{\left|F C N_{i(k)}\right|+\left|F C P_{i(k)}\right|} \cdot\left(M P_{i(k)}-M N_{i(k)}\right)+M N_{i(k)}
$$

In (7), $M P_{i(k)}$ is the month $i$ that the value of the cash flow becomes positive in the scenario $k$ and $M N_{i(k)}$ is the month $i$ that the value of the cash flow is negative just before it becomes positive in scenario $k$.

\section{Results}

A case study was carried out in a large agroindustry, located 170 km from Goiânia, in the Midwest Region of Brazil. The plant's harvest period is between the end of March and the second half of November of each year. The inter-harvest period is the rest of the year, the end of November to the beginning of March, when production does not take place and is destined for maintenance. The annual average of sugar cane production is $2,336,982$ tons, that produces an average of 80,101,217 liters of ethanol and 3,336,477 sacks of sugar.

\section{A. Stochastic Model of the Random Variable Ethanol Production}

Fig. 2 shows the monthly historical data of ethanol production from January 2007 to December 2016. It could be seen the presence of seasonality and reversion to an average value.

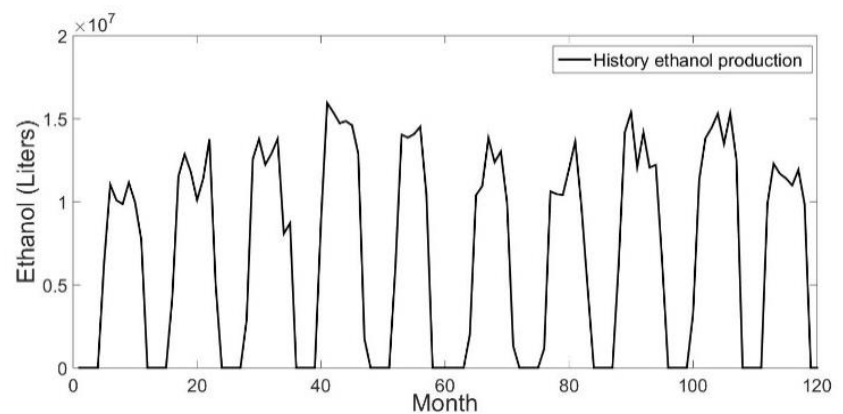

Fig. 2 - History of the random variable ethanol production.

From the historical data is was possible: i) to obtain the monthly seasonally indices (shown in Table I), and ii) to estimate the parameters of the stochastic model used to predict the time series of the random variable ethanol production (shown in Table II ) [9].
Table I - Seasonally indices

\begin{tabular}{|l|c|}
\hline \multicolumn{1}{|c|}{ Month } & Seasonally indices \\
\hline April & 0.438 \\
\hline May & 1.162 \\
\hline June & 1.259 \\
\hline July & 1.219 \\
\hline August & 1.238 \\
\hline September & 1.223 \\
\hline October & 0.992 \\
\hline November & 0.472 \\
\hline
\end{tabular}

The months of January, February, March and December are not presented in Table I because they represent the period of inter-harvest, that is, period that the plant does not operate.

Table II - Parameters of Proposed Model.
\begin{tabular}{|c|c|}
\hline $\bar{E}[1]$ & $10,389,093.16$ \\
\hline$\eta_{E}$ & 0.6397 \\
\hline$\sigma_{E}$ & $4,776,489.71$ \\
\hline
\end{tabular}

For the validation of the stochastic model of the synthetic time series of ethanol production, historical data from January 2007 to December 2013 (7 years) were used for parameter estimation, and historical data from January 2014 to December 2016 (3 years) were used for model validation. Fig. 3 shows the validation simulation.

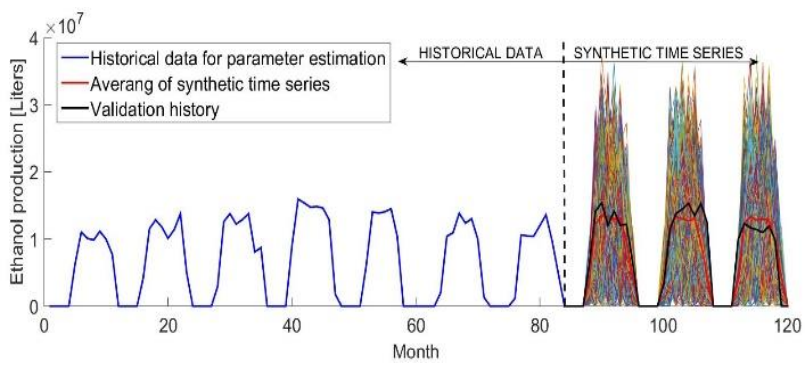

Fig. 3 - Validation of the random variable ethanol production.

By analyzing Fig. 3, it is possible to observe that the model represents the behavior of the random variable in a reliably way. The characteristics of the generated time series indicate the behaviour of mean reversion and the presence of seasonality, being clear the periods of harvest and interharvest. In addition, the red line, that refers to the average value of the generated synthetic time series, is very close to the black line, which represents the history used for the model validation.

\section{B. Vinasse Production Estimation}

Vinasse production is estimated by using the ratio of historical data of the amount of vinasse produced by the ethanol manufacturing process and the amount of ethanol produced. This ratio presents values ranging from 10.68 to 12.06 liters of vinasse generated per liter of ethanol produced. The average of these values is equal to 11.33 , value used to generate the synthetic time series of vinasse production.

Fig. 4 presents the synthetic time series of monthly vinasse production. 
It can be noticed in Fig. 4 that: i) the maximum monthly volume of vinasse can reach $460,000 \mathrm{~m}^{3}$ in a given scenario and ii) the average volume of vinasse to be produced is approximately $150,000 \mathrm{~m}^{3}$.

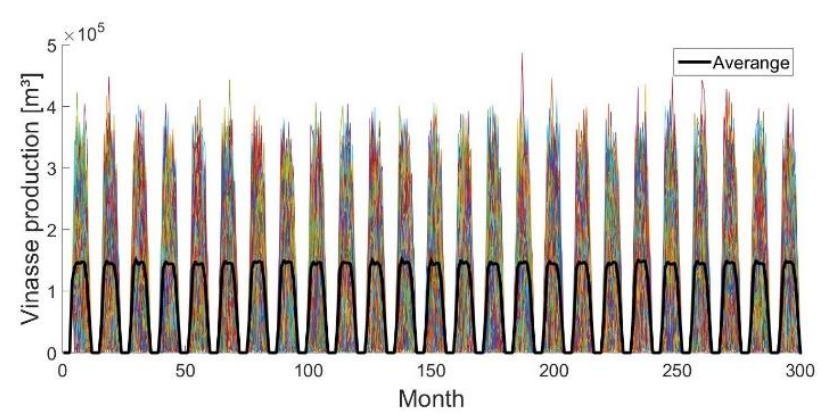

Fig. 4 - Synthetic time series of vinasse production.

\section{Electricity Generation Potential}

The produced vinasse goes to the reactor where the biodigestion process occurs. This reactor was designed to withstand the flow of $3,200 \mathrm{~m}^{3}$ of vinasse per day, with retention time equal to 36 hours. It is important to note that from this moment on, the limitation of the use of vinasse and consequently the generation of biogas occurred. The maximum capacity of biogas generated is equal to 554,000 $\mathrm{m}^{3}$ per month and the average is maintained in approximatelly $500,000 \mathrm{~m}^{3}$ per month.

In this research it was adopted the following assumptions: i) lower calorific power of biogas equal to $5.9697 \mathrm{kWh} / \mathrm{m}^{3}$; ii) efficiency of the motor generator group equal to $40 \%$ and iii) 720 hours of operation per month.

Figure 5 presents the synthetic time series of the electrictricity generation potential that can be produced by the sugar cane agroindustry.

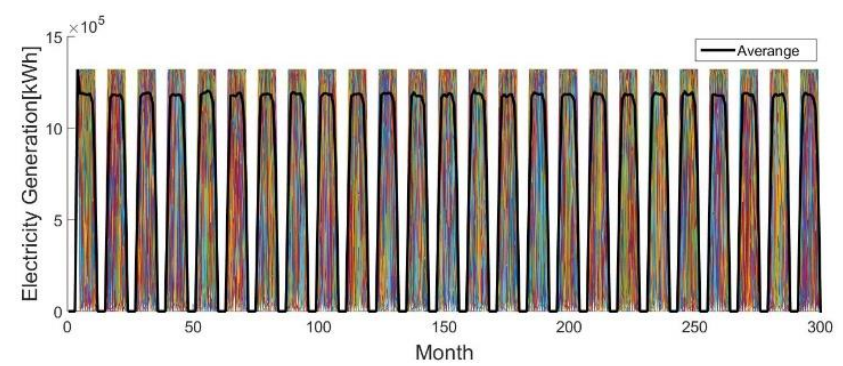

Fig. 5 - Synthetic time series of electricity generation.

It is possible to observe the effect of seasonality present on ethanol production in the time series of the electricity production. The maximum and the average values of electricity production are approximately 1,3 $\mathrm{MWh} /$ month and to $1,1 \mathrm{MWh} / \mathrm{month}$, respectivelly.

\section{F. Cash Flow}

It was considered that all energy produced was sold in the RCE, where the sale price of electricity was defined as the price negotiated for the sale of electricity generated by biogas plants in an auction that held in 2016.
Table III presents the taxes applied to gross revenue, and Table IV the economic and technical assumptions used in the simulation.

Table III - Taxes applied.

\begin{tabular}{|l|c|}
\hline PIS & $0.65 \%$ of Gross Revenue \\
\hline COFINS & $3 \%$ of Gross Revenue \\
\hline CSLL & $\begin{array}{r}9 \% \text { on the basis of taxation of PBIT } \\
\text { IR }\end{array}$ \\
$\begin{array}{r}1.2 \% \text { for up to } 240 \text { thousand/year } \\
2.0 \% \text { on operating surplus }\end{array}$ \\
\hline
\end{tabular}

Table IV - Data used in the simulation.

\begin{tabular}{|c|c|}
\hline Project Lifespan (years) & 25 \\
\hline Reactor cost of investment $\left(\mathrm{R} \$ / \mathrm{m}^{3}\right)$ & $1,006.77$ \\
\hline Investment cost of MGG $20 \mathrm{~kW}(\mathrm{R} \$)$ & $10,7307.00$ \\
\hline Investment cost of MGG $32 \mathrm{~kW}(\mathrm{R} \$)$ & $10,9917.00$ \\
\hline Investment cost of MGG $55 \mathrm{~kW}(\mathrm{R} \$)$ & $14,6867.00$ \\
\hline Investment cost of MGG $77 \mathrm{~kW}(\mathrm{R} \$)$ & $71,7163.00$ \\
\hline Investment cost of MGG $160 \mathrm{~kW}(\mathrm{R} \$)$ & $37,7547.00$ \\
\hline Efficiency of MGG (\%) & 40 \\
\hline Price of energy in RCE (R $\$ / M W h)$ & $251.00^{1}$ \\
\hline $\begin{array}{l}\text { Minimum Attractiveness Rate of Return } \\
\text { (MARR) (\% p.a.) }\end{array}$ & $8^{2}$ \\
\hline Investment Rate (\% p.a.) & $8^{2}$ \\
\hline Financing Rate (\% p.a.) & $8.4^{3}$ \\
\hline $\begin{array}{l}\text { Operation and Maintenance of the Assembly } \\
\left(\mathrm{R} \$ / \mathrm{m}^{3}\right)\end{array}$ & 16.05 \\
\hline $\begin{array}{l}\text { TUST - Distribution System Use Fee } \\
\text { (R\$/kWmês) }\end{array}$ & 1.5 \\
\hline $\begin{array}{l}\text { ANEEL }{ }^{4} \text { inspection fee applied to net revenue } \\
(\%)\end{array}$ & 5 \\
\hline Linear Depreciation (years) & 25 \\
\hline \multicolumn{2}{|c|}{$\begin{array}{l}{ }^{1} \text { According to the } 23 \text { New Energy Auction A-5 held in } 2016 . \\
{ }^{2} \text { Equal to Cost of Equity calculated through Technical Note } \mathrm{n}^{\circ} 89 / 2014- \\
\text { SER/ANEEL. } \\
{ }^{3} \text { Equal to the Cost of Capital of Third Parties calculated through the } \\
\text { Technical Note }{ }^{\circ} 89 / 2014-\text { SER/ANEEL. } \\
{ }^{4} \text { National Electric Energy Agency of Brazil. }\end{array}$} \\
\hline
\end{tabular}

\section{Indicators of Economic Viability}

In this section it is presented the probability distributions of the indicators of economic viability NPV, MIRR and Discounted Payback.

Fig. 6 shows the probability distribution of NPV. The area represented by the red color indicates the probability of the project being unfeasible (VPL $<0)$. The blue area indicates the probability of the project being viable (VPL $\geq 0)$.

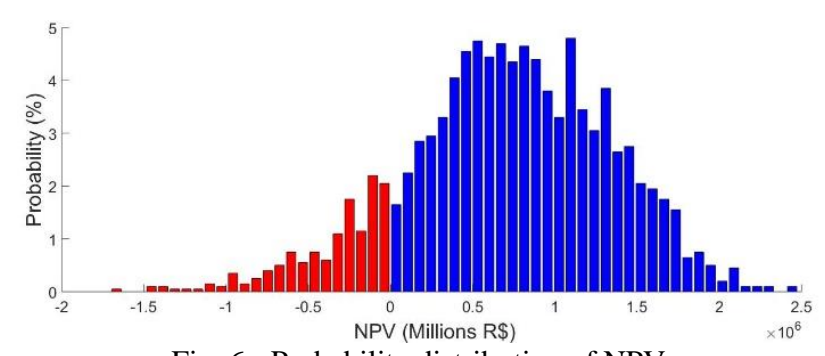

Fig. 6 - Probability distribution of NPV. 
For this analysis the expected value of NPV (E[NPV]) and the risk $(\sigma[\mathrm{NPV}])$ were equal to $\mathrm{R} \$ 711.347,72$ and $\mathrm{R} \$$ $623.784,84$, respectively. The probability of non-return of the investment is equal to $13.20 \%$.

Fig. 7 shows the probability distribution of the MIRR. The area represented by the red color indicates the probability of the project being unfeasible (MIRR $<$ MARR). Tohe color in blue indicates the probability of the project being feasible (MIRR $\geq$ MARR).

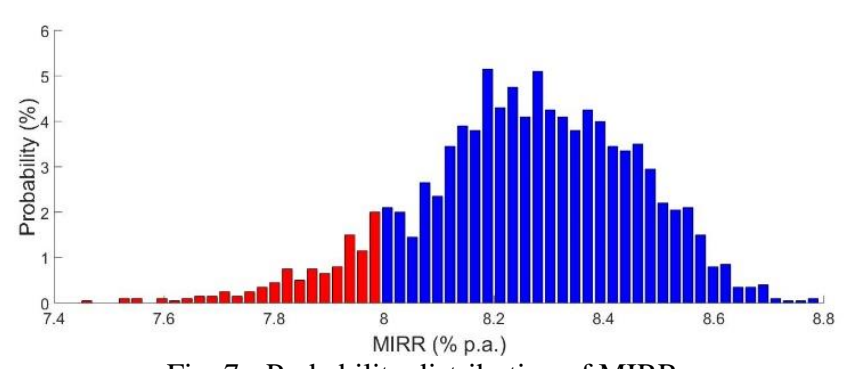

Fig. 7 - Probability distribution of MIRR.

For this analysis the expected value of MIRR (E[MIRR]) and the risk ( $\sigma[\mathrm{MIRR}])$ were equal to $8.26 \%$ and $0.21 \%$, respectively. The probability of non-return of the investment is equal to $10.35 \%$.

Fig. 8 shows the probability distribution of the Discounted Payback. In this figure the area in blue represents the probability of the payback being less than the useful life of the project, which in this case is 300 months. This area indicates the feasibility of the project, as the return on investment will occur before the end of its useful life.

The area represented by the red color represents the probability of the payback being greater than the useful life of the project, indicating its non-viability.

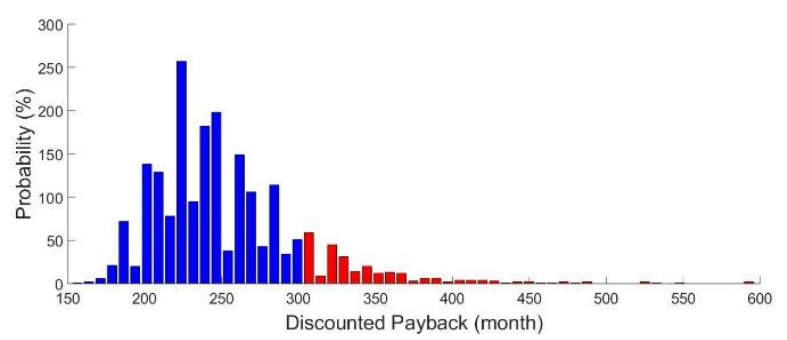

Fig. 8 - Probability distribution of Discounted Payback.

For this analysis the expected value of Discounted Payback $(\mathrm{E}[$ Payback]) and the risk ( $\sigma[$ Payback]) were equal to 253 months and 59 months, respectively. Probability of the payback being less than the useful life of the project is $86,79 \%$.

\section{Conclusion}

This paper presented a methodology for risk analysis of investments in electricity generation from the energetic use of biogas from the biodigestion of vinasse produced in sugarcane agroindustries with commercialization of electricity in the RCE.
From the appropriate stochastic modeling it was possible to predict the behavior of ethanol production, which is directly related to the production of vinasse. Such modeling was validated, presenting characteristics of mean reversion and seasonality.

The risk analysis indicated the economic viability of the project, since most scenarios present NPV greater than zero, MIRR greater than the MARR and Discounted Payback lower than project lifespan.

\section{Acknowledgement}

The authors would like to thank agroindustry managers for providing providing the necessary data to undertake this research project.

\section{References}

[1] M. A. F. D. S. Nogueira; M. D. S. Garcia. Management of industrial sugar-energy sector waste: a power plant case study in Rio Brilhante municipality Mato Grosso do Sul (in Portuguese). Journal of the Center for Natural and Exact UFSM, Santa Maria, v. 17, p. 3275-3283, Dec 2013.

[2] L. Cortez; P. Magalhães; J. HappiMain by-products of the sugarcane agroindustry and its valorization. Brazilian Journal of Energy, v.2, n. 2, 1992.

[3] M. M. R. Poveda. Economic and Environmental Analysis of Vinasse Processing with Energy Utilization (in Portuguese). Master Thesis. Post-Graduation in Energy. Institute of Energy and Environment. University of Sao Paulo. São Paulo, 2014.

[4] N. J. de Castro; G. A. Dantas; A. L. S. Leite; R. Brandão. Bioelectricity and the alcohol and sugar industry: possibilities and limits. Rio de Janeiro: Synergia: Eletrobrás: GESEL, UFRJ,2008.

[5] V. C. Micuanski, Technical and Economic Feasibility of Using Vinasse for Electricity Generation (Case Study) (in Portuguese). Master Thesis. Graduate Program in Energy Engineering in Agriculture. State University of Western Paraná. Cascavel, 2014.

[6] A. Rodrigues, R. F. Santos, A. B. Avaci, H. A. Rosa, L. I. Chaves, E. Gasparin. Estimation of the Power Generation Potential from Vinhaça. Acta Iguazu Magazine, Cascavel, v.1, n.2, p.80-93,2012.

[7] L.M. Ozorio; C. L. B. Pinto; T. K. N. Baidya; L. E. T. Brandão. (Mean Reversion with Drift and Real Options in Steel Industry. Brazilian Journal of Finance, v. 10, p. 215241, 2012.

[8] A. N. Costa; E. G. Domingues; G. P. Medeiros; D. Pinheiro Neto; A. J. Alves; W. C. Pacheco. Investment Risk Analysis in the Use of Landfill Biogas for Electricity Generation. In: International Conference on Renewable Energy and Power Quality Journal (ICREPQ'16). Madrid, 2016.

[9] L. S. Pinto; E. G. Domingues; D. Pinheiro Neto; S Ramalho; M. H. E. Tschudin; G. P. Medeiros.Risk Analysis of the Electric Power Generation Potential from Biogas Coming from Vinasse Biodigestion. In: IEEE II Congreso Chileno De Ingeniería Eléctrica, Electrónica, Tecnologías De La Información Y Comunicaciones (IEEE CHILECON 2017). Pucón, 2017.

[10] A. Damodaran. Valuation of Investments - Tools and Techniques for Determining the Value of Any Assets. 2 ed. Rio de Janeiro: Qualitymark,2010.

[11] N. Casarotto Filho; B. H. Kopittke. Analysis of Investments: Financial Mathematics, Economic Engineering, Decision Making, Business Strategy.10. ed. São Paulo: Atlas, 2007.

[12] H. G. Brazil. Modern Investment Assessment. 1. ed. Rio de Janeiro: Qualitymark, 2002. 